Journal of Clinical Investigation

Vol. 43, No. 5, 1964

\title{
Effect of Serotonin on Glycogen Metabolism in Isolated Rat Liver *
}

\author{
Robert A. Levine, $\dagger$ Leroy A. Pesch, $\ddagger$ Gerald Klatskin, and \\ Nicholas J. Giarman \\ (From the Departments of Internal Medicine and Pharmacology, Yale University School of \\ Medicine, New Haven, Conn.)
}

In the invertebrate liver fluke, Fasciola hepatica, there is evidence that 5-hydroxytryptamine (serotonin) increases glycolysis $(1,2)$, glycogenolysis (1), and phosphorylase activity (3). However, previous studies in mammalian liver, in vitro and in vivo, have yielded conflicting results concerning the effect of serotonin on hepatic glycogen content, hepatic phosphorylase, and blood glucose. Some investigators have reported a hyperglycemic action that they have attributed either to liberation of epinephrine from the adrenal medulla $(4,5)$ or to a direct glycogenolytic effect in the liver $(6,7)$. Others have found that serotonin either has no effect on blood glucose or produces hypoglycemia (8-11).

To investigate the direct action of serotonin on hepatic glycogen metabolism, we employed the technique of isolated liver perfusion. The results of our studies indicate that exogenous or endogenous serotonin causes glycogenolysis, hyperglycemia, and stimulation of hepatic phosphorylase activity in the isolated perfused rat liver.

* Submitted for publication May 27, 1963; accepted December 26, 1963.

Presented in part at the joint meeting of the American Society for Clinical Investigation and the American Federation for Clinical Research, Atlantic City, N. J., April 30, 1963.

Supported in part by research grant A-5966 from the National Institute of Arthritis and Metabolic Diseases, U. S. Public Health Service.

$\dagger$ Postdoctoral trainee, supported by training grant 2A-5180 from the National Institute of Arthritis and Metabolic Diseases, U. S. Public Health Service.

Present address : Metabolic Division, U. S. Army Medical Research and Nutrition Laboratory, Fitzsimons General Hospital, Denver, Colo.

$¥$ Present address: Rutgers Medical School, New Brunswick, N. J.

\section{Materials and Methods}

Liver-donor animals. Adult male Sprague-Dawley rats weighing 400 to $500 \mathrm{~g}$ served as blood and liver donors. They were maintained on Purina lab chow and received food and water ad libitum until immediately before sacrifice. Blood for perfusion was obtained by cardiac puncture, with heparin as the anticoagulant.

Perfusion technique. The procedure employed for the removal of liver and its perfusion was that described by Miller and colleagues $(12,13)$. Donor rats were anesthetized with pentobarbital sodium, $35 \mathrm{mg}$ per $\mathrm{kg}$, intraperitoneally. In each experiment the bile duct was cannulated with a fine polyethylene catheter to permit measurement of bile flow as an index of hepatic function. The perfusate contained a mixture of 50 to $70 \mathrm{ml}$ of heparinized whole rat blood and 25 to $35 \mathrm{ml}$ of Ringer's solution with no added glucose. Blood was oxygenated with a mixture of $5 \% \mathrm{CO}_{2}$ and $95 \%$ oxygen. The oxygenated, heparinized blood (arterial perfusate) entered the liver by gravity through a glass cannula in the portal vein, at a hydrostatic pressure of $14 \mathrm{~cm}$ blood, and returned to the blood reservoir via a cannula in the thoracic portion of the inferior vena cava (hepatic venous effluent). Hepatic blood flow in milliliters per minute was estimated by counting the drops of effluent coming from a precalibrated cannula in the inferior vena cava. Vasomotor changes were considered significant when blood flow decreased more than $10 \%$ of the initial or immediately preceding value.

A specially designed collecting chamber for sampling hepatic venous effluent before mixing with arterial perfusate was employed to make simultaneous determinations on venous and arterial blood possible. The apparatus is illustrated in Figure 1.

At appropriate intervals, samples of blood were collected and lobes of liver removed for determination of blood glucose and hepatic glycogen and phosphorylase. The liver specimens were also studied histologically with hematoxylin-eosin and Masson stains.

Drug administration. Amounts of drugs shown in the text were diluted in Ringer's solution and administered through a polyethylene catheter just proximal to the portal vein cannula, either by rapid injection or by constant infusion at a rate of $2 \mathrm{ml}$ per hour with a calibrated motor-driven syringe. 


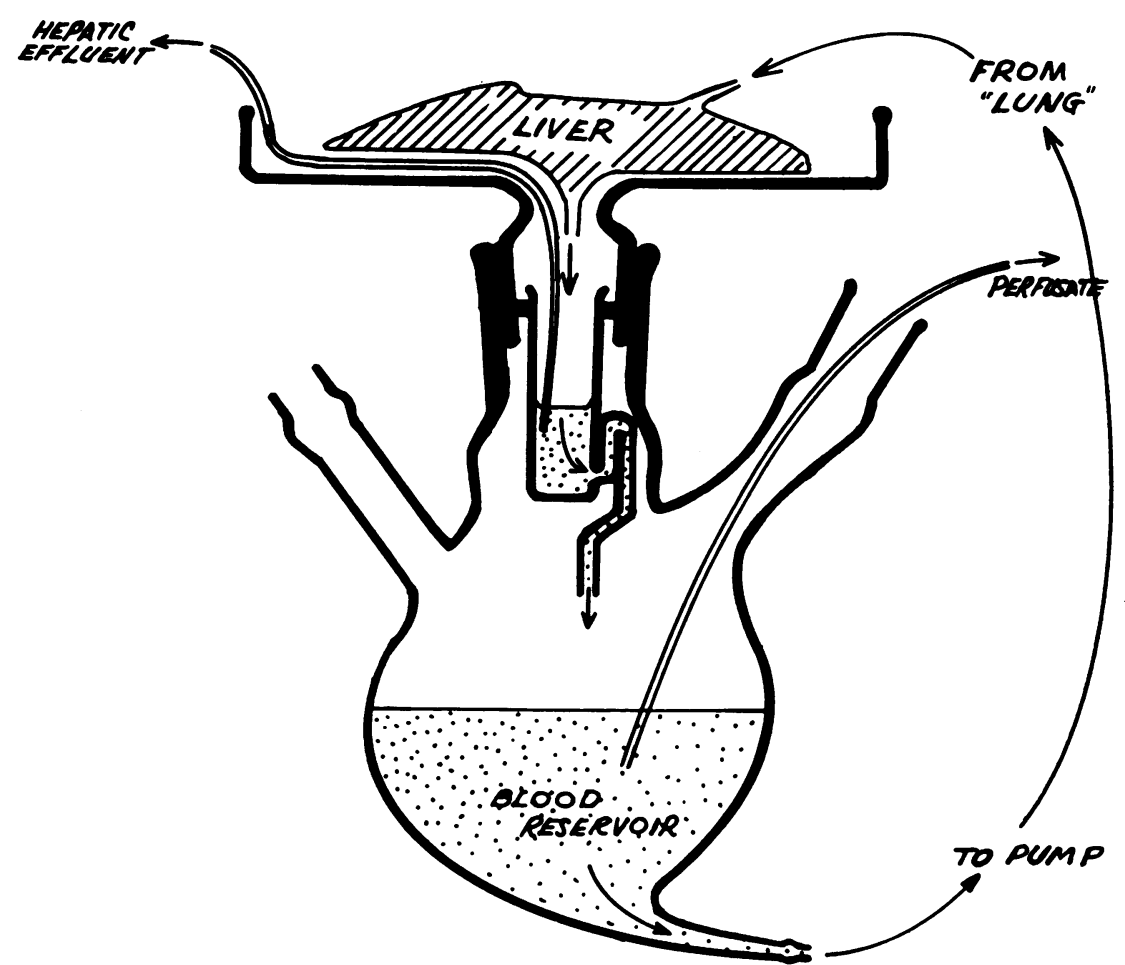

Fig. 1. Siphon collection Chamber for sampling hepatic venous effluent

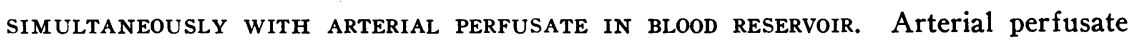
from lung enters liver, and excess blood, coming also from lung by means of an overflow tube (not shown), enters the reservoir (opening at left of figure) and mixes with venous effluent entering from siphon collection chamber. Blood samples were removed via cannulas in collection chamber and reservoir.

Serotonin creatinine sulfate 1 was introduced in doses ranging from $16 \mu \mathrm{g}$ to $1.6 \mathrm{mg}$ of the acid salt by rapid injection over a 2 -minute period, or from 4.1 to $240 \mu \mathrm{g}$ per minute by constant infusion. 1-methyl-[methylergonovine], also known as UML-491 or Sansert, ${ }^{2}$-hydroxytryptophan ${ }^{1}$ (5-HTP), l-epinephrine bitartrate, ${ }^{1}$ histamine dihydrochloride, ${ }^{3}$ and glucagon ${ }^{4}$ were infused in several experiments, and Ringer's solution served as a control in these and other experiments.

In vivo rat experiments. Serotonin, 5-HTP, and UML-491 were administered by the subcutaneous, intraperitoneal, or intravenous route to intact, adult, fed rats. Blood for glucose determinations was taken by cardiac puncture before treatment and at intervals after drug administration.

Blood glucose was determined by the Nelson method utilizing Somogyi protein-free filtrates of duplicate $1-\mathrm{ml}$ blood samples (14).

1 Sigma Chemical Co., St. Louis, Mo.

2 Sandoz Pharmaceuticals, Hanover, N. J.

${ }^{3}$ Nutritional Biochemicals Corp., Cleveland, Ohio.

4 Eli Lilly and Co., Indianapolis, Ind. Kindly supplied by Dr. W. R. Kirtley.
Serotonin was determined on 3-ml blood samples by the method of Amin, Crawford, and Gaddum (15) and by a bioassay performed on the isolated clam heart, Venus mercenaria, according to the method of Twarog and Page (16).

Liver glycogen. Approximately 3 minutes after establishing liver perfusion and at intervals thereafter, minor hepatic lobes, or occasionally an additional small portion of a major lobe, were ligated, quickly excised, and placed into weighed $50-\mathrm{ml}$ centrifuge tubes containing $30 \%$ potassium hydroxide. The tubes were rapidly reweighed and heated to boiling for 45 minutes. Glycogen was then determined in duplicate by the method of Good, Kramer, and Somogyi (17), using Nelson's method to determine glucose after hydrolysis. Glycogen values are expressed as milligrams of glucose per gram of wet tissue after hydrolysis.

Hepatic phosphorylase. Excised liver samples were immediately frozen in acetone-dry ice. All subsequent procedures were performed at ice bath temperatures. Two per cent homogenates (wt/vol) were prepared in distilled water with a Potter-Elvehejm homogenizer for determination of phosphorylase activity according to the method of Hers (18). The inorganic phosphorous liber- 

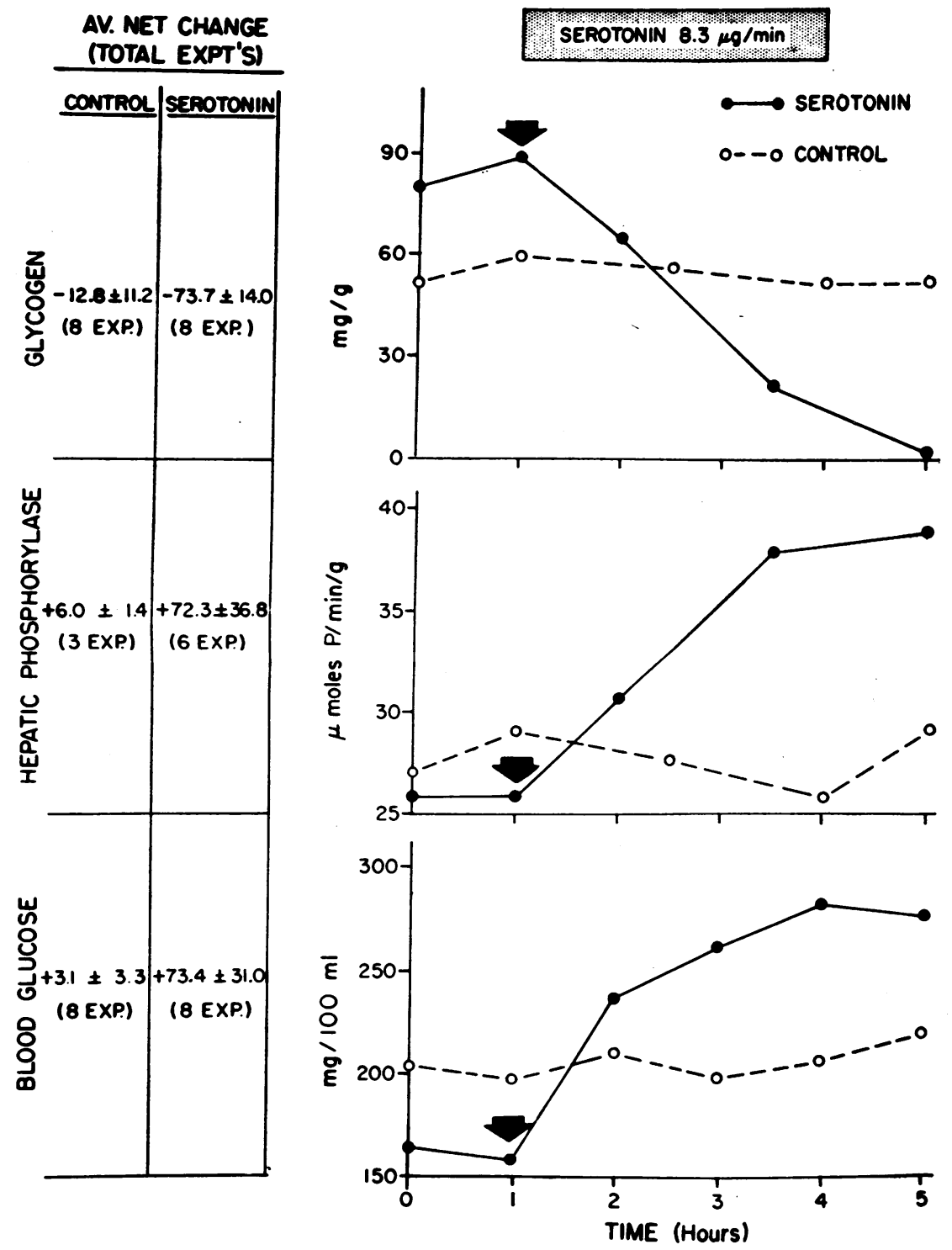

Fig. 2. TyPical SERotonin and CONTROL PERfusions SHOWING INCREASED GLYCOGENOLYSIS, PHOSPHORYLASE ACTIVITY, AND BLOOD GLUCOSE AFTER ENDOPORTAL ADMINISTRATION OF SEROTONIN. At the left, the average and SD of the individual net percentage of changes between time of serotonin or Ringer's solution infusion (1 hour) and end of perfusion ( $4 \frac{1}{2}$ to 6 hours) is tabulated for both serotonin and control groups.

ated during glycogen synthesis from glucose-1-phosphate was measured after 10 minutes incubation at $37^{\circ} \mathrm{C}$ by the Fiske-SubbaRow method (19), phosphorylase activity being expressed as micromoles of phosphate $(\mathrm{P})$ liberated per minute per gram of wet weight of liver. Appropriate controls were included to enable corrections for zero-time conditions.

\section{Results}

Glycogen metabolism in control and serotonin studies. Figure 2 compares the results in a typical serotonin and control perfusion experiment. Endoportal administration of serotonin caused progressive glycogenolysis, stimulation of hepatic 
TABLE I

Effect of serotonin on the isolated perfused rat liver

\begin{tabular}{|c|c|c|c|c|c|c|c|c|}
\hline \multirow[b]{2}{*}{ Serotonin } & \multirow{2}{*}{$\begin{array}{c}\text { Duration } \\
\text { of } \\
\text { perfusion }\end{array}$} & \multirow{2}{*}{$\begin{array}{c}\text { Vasomotor } \\
\text { effect* }\end{array}$} & \multicolumn{2}{|c|}{ Hepatic glycogen } & \multicolumn{2}{|c|}{ Hepatic phosphorylase } & \multicolumn{2}{|c|}{ Blood glucose } \\
\hline & & & Control $\dagger$ & $\overline{\text { Final }}$ & Controlt & Final & Control $\dagger$ & $\overline{\text { Final }}$ \\
\hline$\mu g / \min$ & hours & & \multicolumn{2}{|c|}{$m g / g$} & \multicolumn{2}{|c|}{$\mu$ moles $P / \min / \mathrm{g}$} & \multicolumn{2}{|c|}{$m g / 100 m l$} \\
\hline 4.1 & 5 & 0 & 110 & 45 & 18.8 & 45.0 & 180 & 305 \\
\hline 6.8 & 6 & 0 & 130 & 30 & 25.3 & 42.8 & 128 & 285 \\
\hline 8.3 & 5 & 0 & 90 & 2 & 25.4 & 38.3 & 160 & 280 \\
\hline 16.0 & 4.5 & 0 & 60 & 17 & 30.3 & 43.2 & 195 & 390 \\
\hline 88.0 & 6 & + & 120 & 38 & & & 200 & 310 \\
\hline 120.0 & 5 & + & 68 & 11 & 25.0 & 45.1 & 184 & 250 \\
\hline 240.0 & 5 & + & 118 & 55 & & & 200 & 315 \\
\hline 240.0 & 6 & + & 85 & 18 & 41.3 & 61.8 & 78 & 156 \\
\hline
\end{tabular}

$* 0=$ absent,$+=$ present.

† Control value taken 60 minutes after start of liver perfusion and immediately before serotonin infusion.

phosphorylase activity, and concomitant hyperglycemia. Because of biological variations among donor rats, initial glycogen levels varied from 20 to $130 \mathrm{mg}$ per $\mathrm{g}$, phosphorylase from 18 to 41 $\mu$ moles $\mathrm{P}$ per minute per $\mathrm{g}$, and glucose from 78 to $260 \mathrm{mg}$ per $100 \mathrm{ml}$ in both serotonin and control animals 1 hour after establishing perfusion. However, the stability of these different values during each control experiment was notable. The results in 14 other experiments were similar to those depicted in Figure 2 and are summarized at the left of the figure. Glycogen decreased in every serotonin experiment, as shown in Table I. The average and SD of the individual percentage decreases from the initial 1-hour value were 73.7 $\pm 14.0 \%$ in 8 serotonin experiments compared to a $12.8 \pm 11.2 \%$ decline over the same intervals in 8 controls. This difference is significant for the serotonin group $(\mathrm{p}<0.001)$. Hepatic phosphorylase activity increased $72.3 \pm 36.8 \%$ from

TABLE II

Early changes in glucose concentration of perfusate after endoportal administration of serotonin

\begin{tabular}{ccccc}
\hline \multicolumn{5}{c}{ Blood glucose } \\
Serotonin & Control* Final & Interval & Net increase \\
\hline$\mu g$ & \multicolumn{2}{c}{$m g / 100 m l$} & $\min$ & $\%$ \\
16 & 184 & 218 & 4 & 18.5 \\
16 & 180 & 221 & 8 & 22.8 \\
16 & 195 & 236 & 12 & 21.0 \\
16 & 200 & 242 & 16 & 21.0 \\
16 & 128 & 154 & 20 & 20.3 \\
& & & & Mean $20.7 \pm 1.5 \dagger$ \\
$8.3 / \mathrm{min}$ & 160 & 208 & 20 & 30.0
\end{tabular}

* Control value taken 60 minutes after start of liver perfusion and immediately before single rapid serotonin injection (16 $\mu \mathrm{g})$ or continuous infusion ( $8.3 \mu \mathrm{g}$ per minute). the 1-hour level in 6 serotonin perfusions but only $6.0 \pm 1.4 \%$ in 3 controls. This difference is also significant for the serotonin group $(\mathrm{p}<0.025)$. Blood glucose increased $73.4 \pm 31.0 \%$ above its 1-hour value in 8 serotonin experiments and $3.1 \pm$ $3.3 \%$ in 8 controls, which is again a significant difference for the serotonin group $(p<0.001)$.

There was considerable variation in the rate of change in liver glycogen, phosphorylase, and blood glucose. Figure 3 depicts the mean values and $\mathrm{SD}$ for each of these at hourly intervals after serotonin infusion in 8 experiments, expressed as the percentage of initial concentration. Although the initial changes in blood glucose were less than in phosphorylase activity and glycogen content in the first 2 to 3 hours of infusion, a rise in glucose concentration in the perfusing medium was noted as early as 4 to 20 minutes after a single rapid serotonin injection $(16 \mu \mathrm{g})$ in 5 short-term perfusion experiments (Table II). The average and SD of the net percentage of increase in glucose after the acute injection were $20.7 \pm$ $1.5 \%$.

The effects of serotonin on glycogen metabolism were not consistently related to the dose administered, as shown in Table I. In contrast, serotonin's effect on blood flow paralleled the dose administered more closely (vide infra). In no case was hepatic blood flow diminished with doses of serotonin up to $16 \mu \mathrm{g}$ per minute given either rapidly in 5 experiments or by constant infusion in 4 perfusions. An increase in glucose concentration in the perfusing medium was, however, observed in the 5 acute experiments (Table II); and glycogenolysis, hyperglycemia, and an in- 
crease in phosphorylase activity were produced at these low doses in the 4 perfusion experiments (Table I), demonstrating that these responses were independent of the vasomotor effect.

The hepatic glycogen content was determined on several lobes of liver after the same interval of perfusion in 3 control and 3 serotonin experiments employing $8.3,88$, and $240 \mu \mathrm{g}$ per minute, and the variation among the different lobes of the same liver averaged $2.5 \%$ with a SD of $\pm 2.2 \%$ in the 6 cases. This variation was of the same order of magnitude found in excised liver lobes taken from 4 intact control rats $(3.1 \pm 2.6 \%)$.

Decreases in liver glycogen after the infusion of $4^{10^{-4}} \mathrm{M}$ serotonin and $2^{10^{-2}} \mathrm{M}$ 5-HTP were comparable to those observed with $6^{10^{-5}} \mathrm{M}$ epinephrine and $2^{10^{-6}} \mathrm{M}$ glucagon in this isolated system (20). At these molar concentrations, however, glycogenolysis and hyperglycemia after epinephrine or glucagon were more prompt than after serotonin or $5-\mathrm{HTP}$ administration.

Infusions of histamine dihydrochloride, 50 to $100 \mu \mathrm{g}$ per hour, had no effect on glycogen content, blood glucose, hepatic phosphorylase, or blood flow in 3 perfusion experiments.

Bile flow and histology. In both serotonin and control groups, bile flow rates averaged $0.75 \mathrm{ml}$ per hour. Moreover, routine histologic studies, similar in both groups, revealed no significant changes during or after 4 to 6 hours of perfusion.

Studies on hepatic blood flow and serotonin blood levels. In control experiments, hepatic blood flow increased from a mean of $14 \mathrm{ml}$ per minute during the first hour to an average of 20 $\mathrm{ml}$ per minute, a rate that was sustained for the next 2 to 3 hours, and then gradually fell to an average of $17 \mathrm{ml}$ per minute.

As shown in Figure 4, serotonin produced in blood flow a prompt decrease that was approximately proportional to the dose. Control serotonin levels in the venous effluent were only $40 \%$ of those in the arterial perfusate, demonstrating rapid uptake of serotonin by the liver. During the rapid infusion of serotonin, the level of the amine in the venous effluent exceeded that in the arterial perfusate. However, for a period of 4 to 45 minutes after completion of the injection, the liver rapidly and progressively cleared the blood of serotonin, as indicated by the fall in the

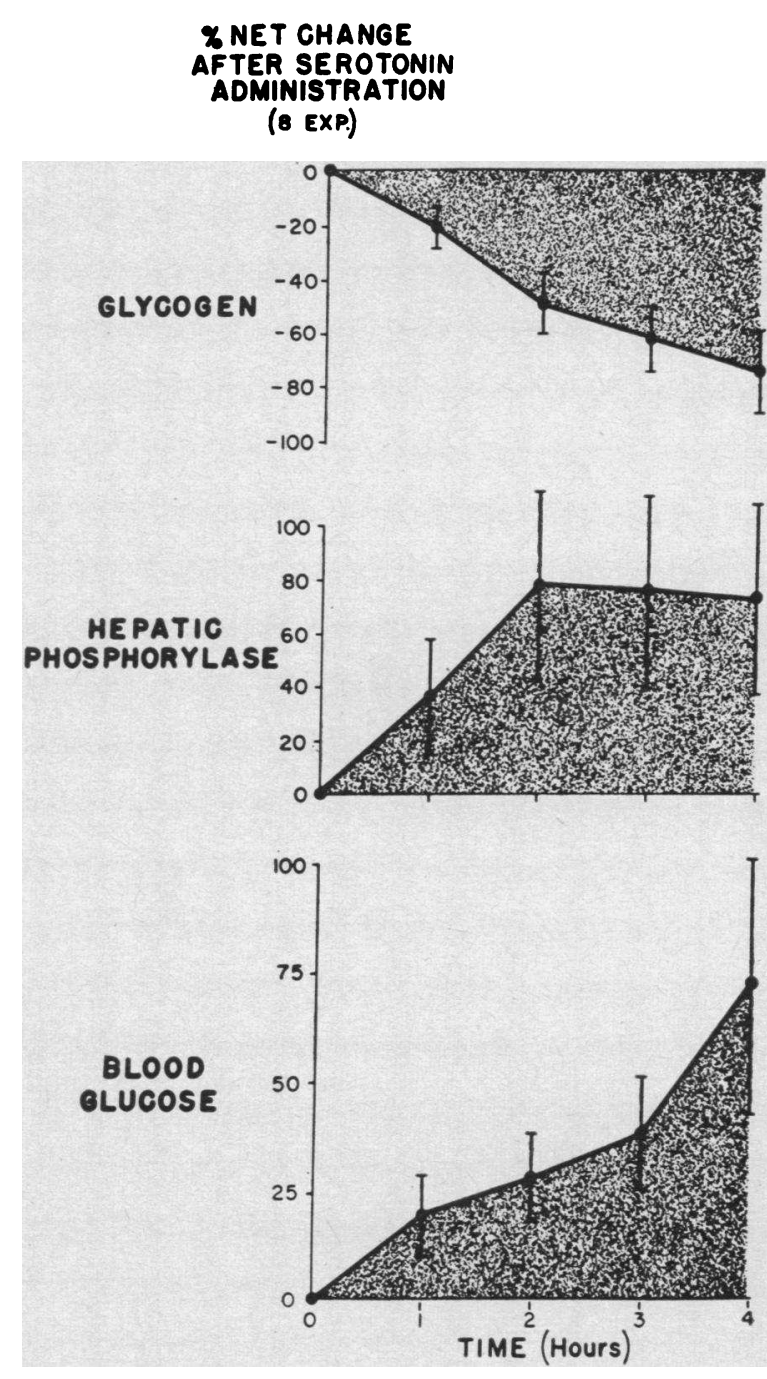

Fig. 3. Mean concentration of hepatic glycogen, PHOSPHORYLASE, AND BLOOD GLUCOSE AT HOURLY INTERVALS AFTER SEROTONIN ADMINISTRATION IN 8 EXPERIMENTS. Values on ordinate expressed as percentage of initial concentration. Phosphorylase activity was performed in 6 of the 8 experiments. Lines extending from each point represent SD.

venous effluent to $60 \%$ of that in the arterial perfusate. In contrast, during 3 perfusions with prolonged continuous serotonin infusions, hepatic venous-arterial perfusate differences disappeared by the third hour. At that time the mean serotonin levels in the venous effluent and arterial perfusate were the same, indicating that the capacity of the liver to clear serotonin was limited and had been exceeded. 


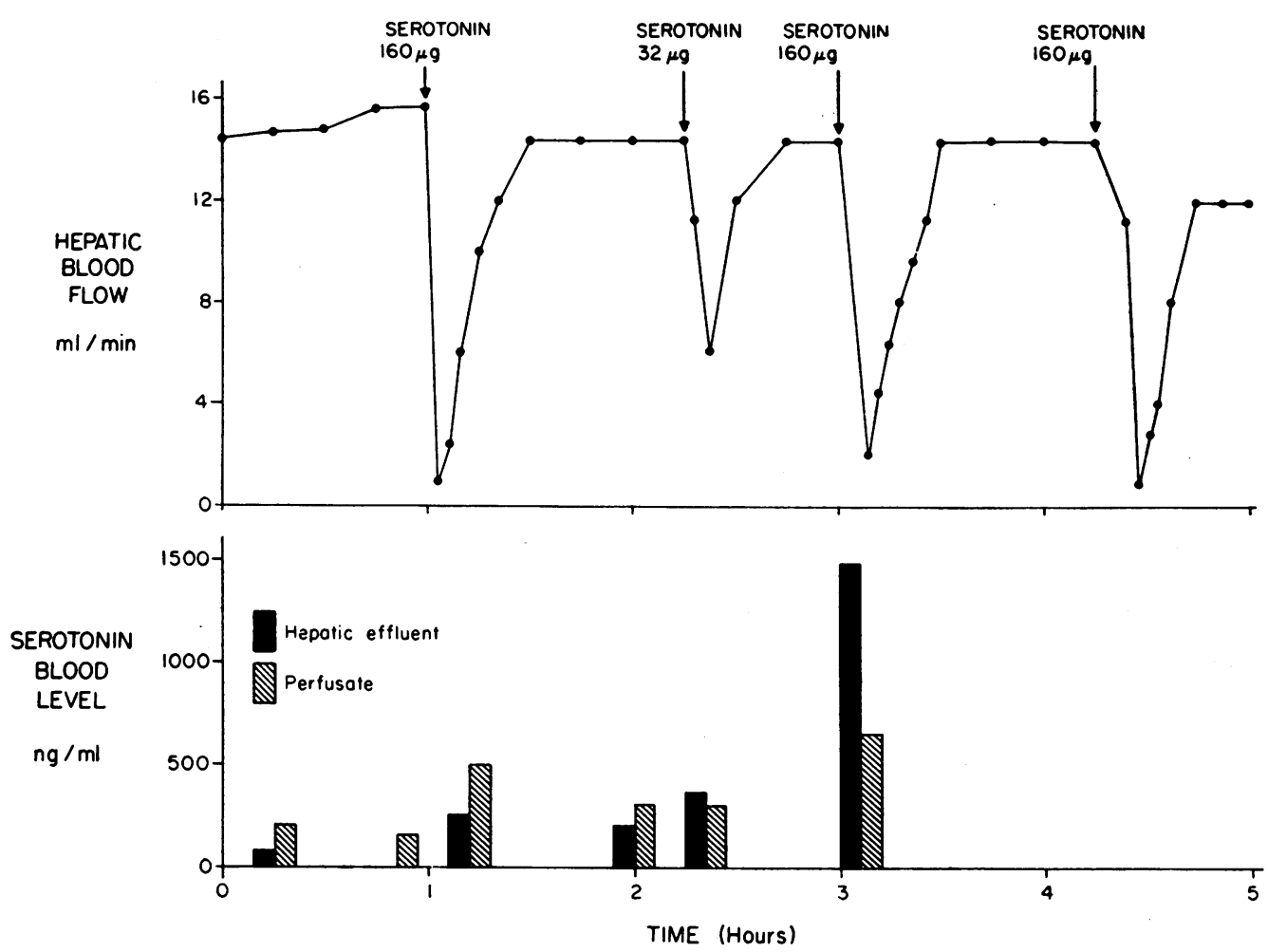

Fig. 4. Relationship between hepatic blood flow ANd SEROtonin blood levels. Hepatic uptake of serotonin was demonstrated before and after serotonin administration (at $\frac{1}{4}, 1 \frac{1}{4}$, and 2 hours) but not during the acute serotonin injection (at $2 \frac{1}{3}$ and 3 hours). Serotonin blood level measured in nanograms $\left(\mathrm{ng}, 10^{-0} \mathrm{~g}\right.$ ) per $\mathrm{ml}$.

Both serotonin-induced vasomotor and glycogenolytic effects occurred at serotonin levels in arterial perfusate that were approximately twice to three times the normal range found in the portal venous blood of intact control rats.

The upper panel of Figure 5, typical of 3 perfusions in which blood flow alone was monitored, shows that the vasomotor response to serotonin progressively diminished after repeated injections of the amine at short intervals (tachyphylaxis). Similarly, tachyphylaxis occurred during the continuous infusion of serotonin, despite progressive increase in blood serotonin levels (lower panel, Figure 5). The upper panel of Figure 5 also shows that epinephrine was capable of reducing blood flow even after pretreatment with serotonin. On a molar basis, the vasomotor effect of epinephrine was about 3 times as great as that of serotonin. This difference was also evident in perfusion experiments in which epinephrine alone was infused.
Studies with $U M L-491$. Figure 6 is a typical example of 4 perfusion experiments showing that UML-491 (arrow), a potent serotonin antagonist, blocked the vasomotor response to serotonin (upper and lower panels) but not that to epinephrine (lower panel).

Figure 7 shows that infusion of UML-491 (solid arrow) before serotonin blocked both its glycogenolytic and vasomotor actions. When the drug was administered after serotonin, however, UML-491 (open arrow) promptly reversed only the vasomotor effect while glycogenolysis and hyperglycemia continued.

Studies with 5-hydroxytryptophan. Figure 8 demonstrates that infusion of 5-HTP, the precursor of serotonin, induced glycogenolysis and hyperglycemia, increased phosphorylase activity, and was associated with a progressive rise in the level of blood serotonin. These effects of endogenously synthesized serotonin on glycogen metabolism of the isolated liver were similar to 


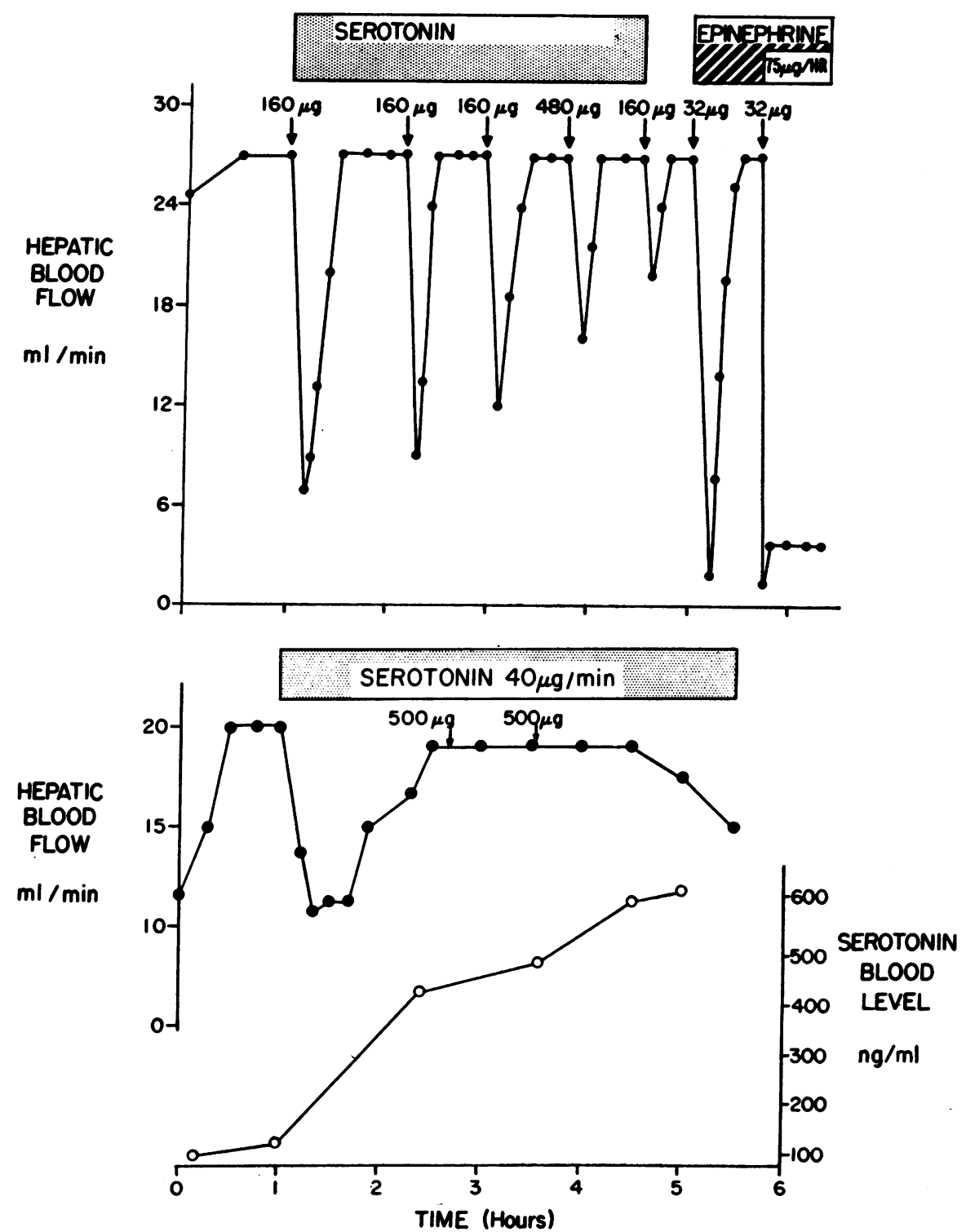

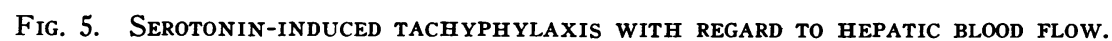
Repeated injections (upper panel) or continuous infusion (lower panel) of the amine results in progressively diminished vasomotor response. The doses of epinephrine in this figure and Figure 6 refer to the bitartrate salt.

those produced by the exogenously administered amine and occurred at comparable serotonin blood levels. Unlike exogenous serotonin, however, 5 -HTP had virtually no effect on hepatic blood flow, as shown in Figure 8, or even when administered by rapid injection in doses as high as $80 \mathrm{mg}$ in 3 other perfusions in which only measurements of blood flow were taken.

In vivo studies. To further evaluate the gly- cemic effect observed in vitro, serotonin was administered to intact rats. The results are shown in Table III. A consistent glycemic effect was observed when serotonin was given subcutaneously or intraperitoneally but not after intravenous injection. As in the in vitro experiments, the increase in blood glucose was not dose-related and was variable.

The in vivo glycemic action of parenteral seroto- 


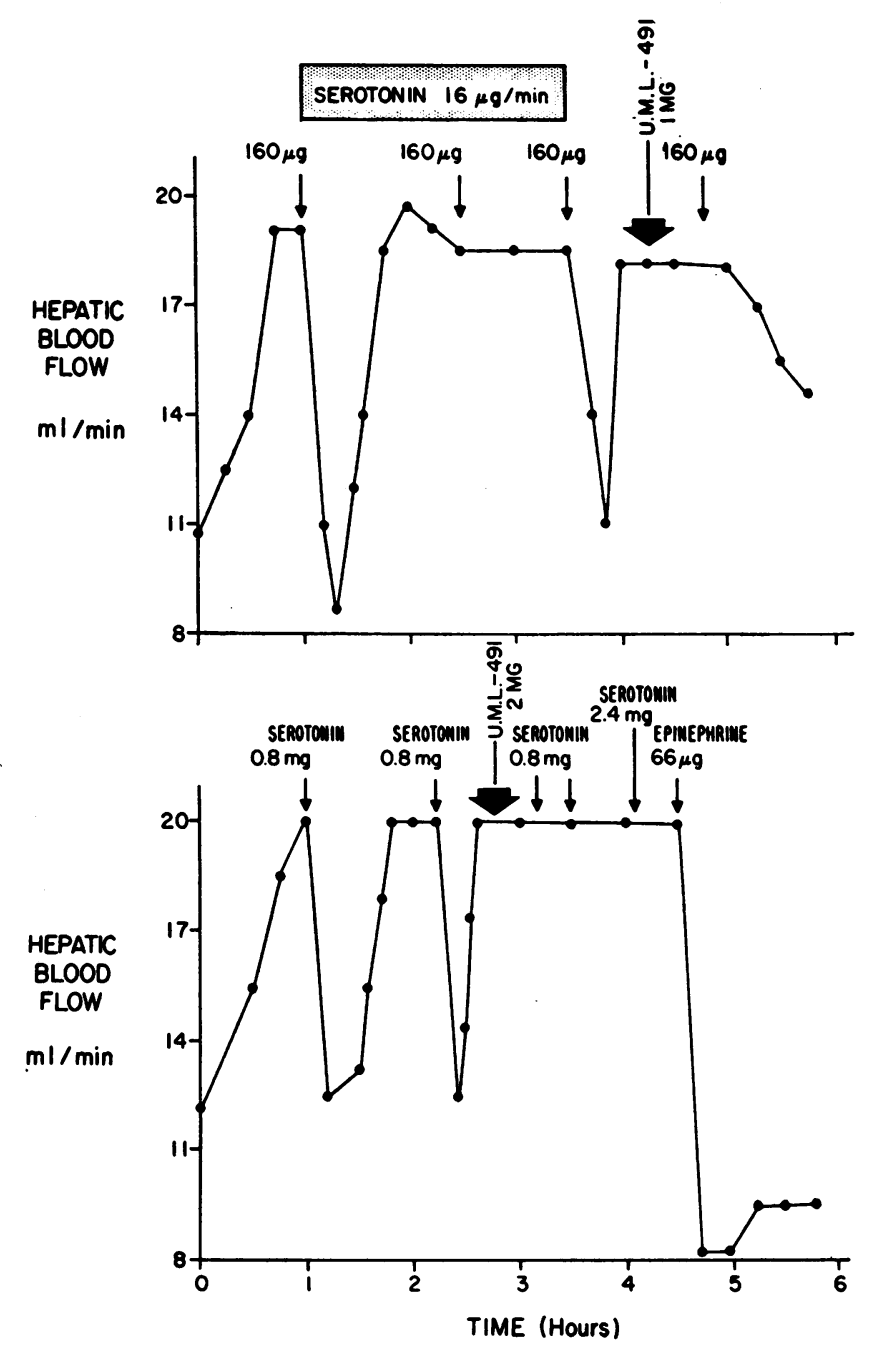

Fig. 6. EFFect OF UML-491 (1-METhyL-[METHYLERGonoVINE] ON THE VASOMOTOR ACTION OF SEROTONIN. UML-491 (arrow) blocks the vasomotor response of serotonin (upper and lower panels) but not of epinephrine (lower panel). Upper panel also shows occurrence of tachyphylaxis, shortly after preceding serotonin injection, and disappearance with prolongation in the interval between injections.

nin was blocked by administration of UML-491 30 minutes earlier, as shown in Table III. Thirty to $60 \mathrm{mg}$ per $\mathrm{kg}$ of 5 -hydroxytryptophan induced a glycemic response when given by the intraperitoneal route but not when administered subcutaneously or intravenously.

\section{Discussion}

The metabolic stability of the isolated perfused liver has made this a useful device for studying the direct actions of a variety of agents on hepatic carbohydrate metabolism (21). Our present studies demonstrate that endoportal administration of serotonin produces glycogenolysis, hyperglycemia, and stimulation of hepatic phosphorylase activity in this isolated system. We made no attempt to determine the minimal dose necessary to elicit these responses. However, a $30 \%$ increase in perfusate glucose concentration was observed in 1 experiment as early as 20 minutes after starting 
a serotonin infusion at the rate of $8.3 \mu \mathrm{g}$ per minute, and a mean $20.7 \pm 1.5 \%$ glucose rise was noted in 5 experiments within 4 to 20 minutes after a single rapid injection of $16 \mu \mathrm{g}$ (Table II). Our studies in vivo (Table III) demonstrate that hyperglycemia follows either subcutaneous or intraperitoneal administration of serotonin, or intraperitoneal injection of 5 -HTP, over a wide dose range.

Serotonin has been shown to enhance the release of epinephrine from the adrenals $(22,23)$. Kobayashi, Ui, and Warashina (4) and Columbo and colleagues (5) suggested that the in vivo glycemic effects induced by serotonin are mediated by epinephrine release from the adrenal gland, since in their experiments serotonin failed to produce hyperglycemia in the adrenalectomized rat and dog. On the other hand, Correll, Lyth, Long,
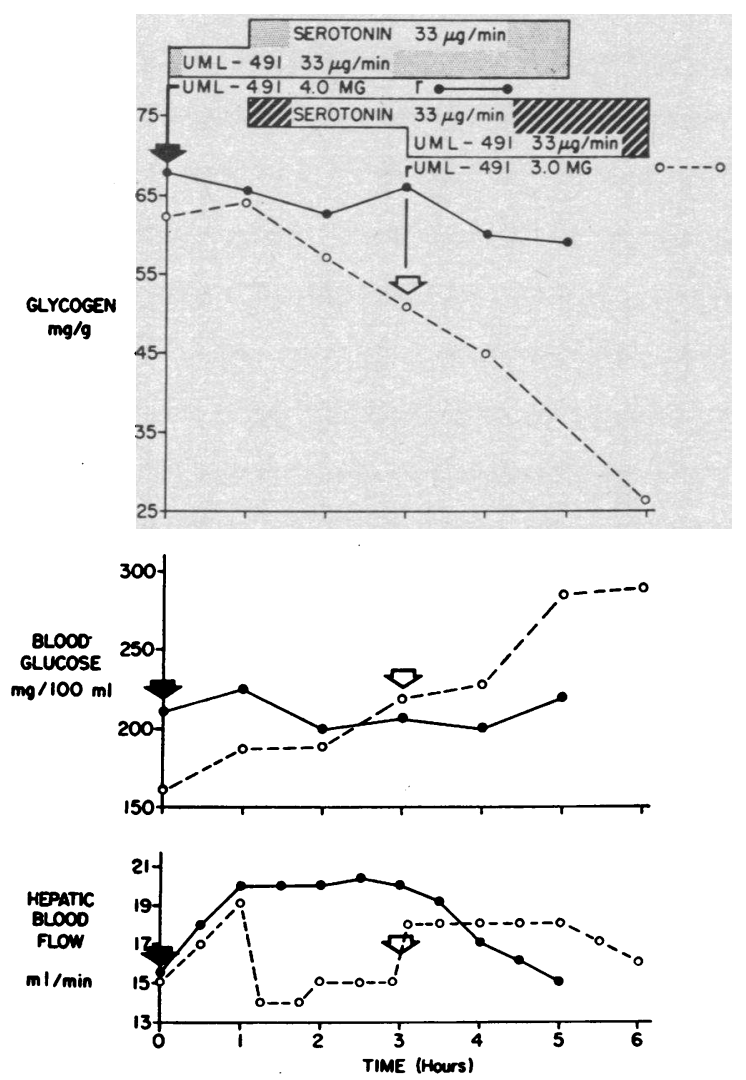

Fig. 7. EFFeCt OF UML-491 BEFore AND AFTER SERoTONIN INFUSION. UML-491 administered before serotonin (solid arrow) blocks both glycogenolytic and vasomotor effects but blocks only the latter effect when UML-491 follows serotonin infusion (open arrow).
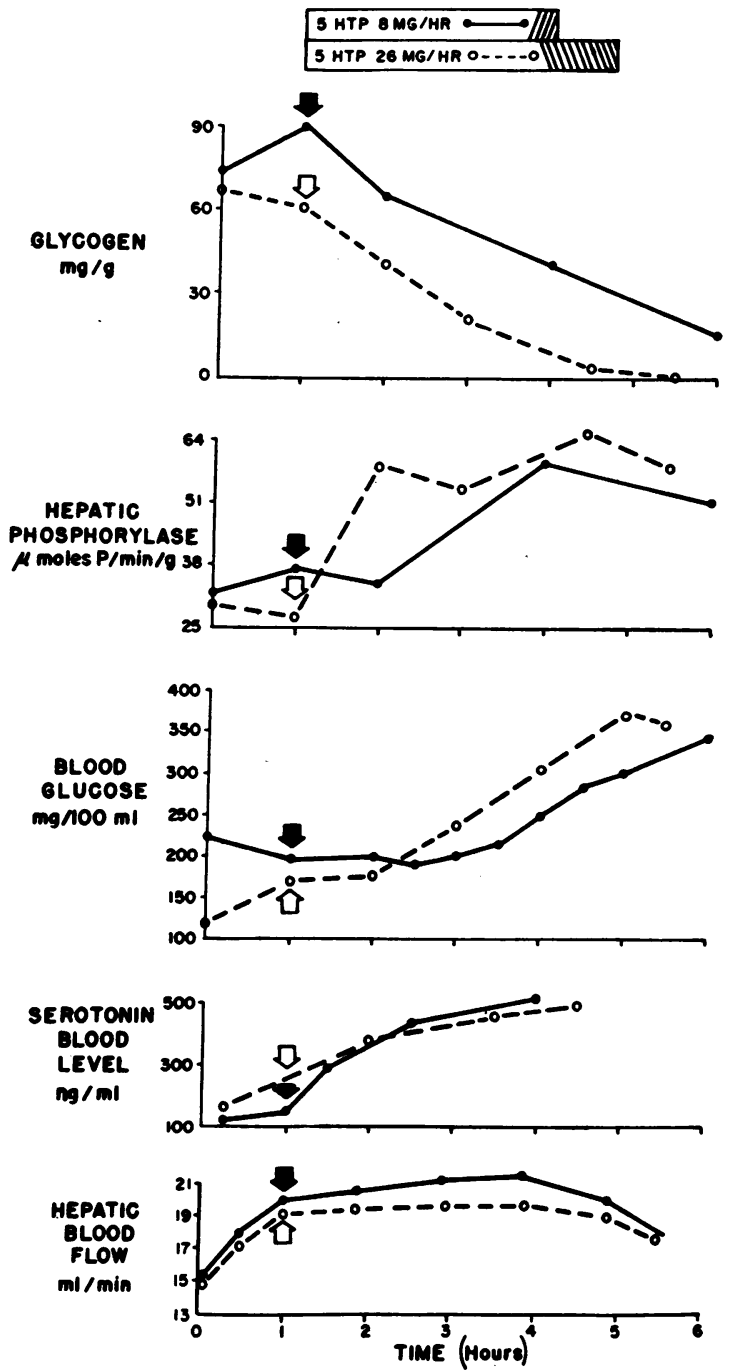

Fig. 8. EFFECt OF 5-HTP (5-H YdROXYTRYPTOPHAN) ON GLYCOGEN METABOLISM. 5-HTP causes glycogenolysis, hyperglycemia, and increased phosphorylase activity. These effects were associated with progressive rise in endogenous serotonin blood levels that were comparable to those found after exogenous administration of the amine.

and Vanderpoel demonstrated serotonin-induced hyperglycemia in adrenalectomized dogs, although they used larger doses (10 $\mathrm{mg}$ per $\mathrm{kg}$ ) (24). The results of our own studies are consistent with their conclusion that epinephrine release is not a prerequisite for the glycemic action of serotonin. Further support for this hypothesis comes from the in vivo studies of Galansino and associates (6) and Gordon and Lipton (7), who 
TABLE III

In vivo glycemic effects of serotonin and 5-hydroxytryptophan

\begin{tabular}{|c|c|c|c|c|c|}
\hline $\begin{array}{c}\text { No. } \\
\text { animals }\end{array}$ & Compound & Dose (range) & Route & $\begin{array}{l}\text { Net mean in- } \\
\text { crease and } \\
\text { range in } \\
\text { blood glucose } \\
\text { concentration }\end{array}$ & $\begin{array}{c}\text { Mean } \\
\text { interval }\end{array}$ \\
\hline & & $m g / k g$ & & $\mathrm{mg} / 100 \mathrm{ml}$ & hours \\
\hline 7 & Serotonin & $0.25-3.0$ & Subcutaneous & $98(15-221)$ & $2 \frac{1}{2}$ \\
\hline 6 & Serotonin & 6.0 & Subcutaneous & $148(41-435)$ & $2 \frac{1}{2}$ \\
\hline 3 & Serotonin & $0.50-3.0$ & Intraperitoneal & $109(90-128)$ & 1 \\
\hline 4 & Serotonin & $6.0-50.0$ & Intraperitoneal & $124(26-299)$ & 1 \\
\hline 3 & Serotonin & 1.0 & Intravenous & $1(-4-6)$ & $\frac{3}{4}$ \\
\hline 3 & UML-491 & 12.0 & Subcutaneous & $11(7-14)$ & $2 \frac{1}{2}$ \\
\hline 3 & $\begin{array}{l}\text { + serotonin } \\
\text { UML-491 }\end{array}$ & $\begin{array}{r}6.0 \\
12.0\end{array}$ & Subcutaneous & $7(5-9)$ & $2 \frac{1}{2}$ \\
\hline 4 & 5-HTP & $30.0-60.0$ & Intraperitoneal & $47(39-60)$ & 1 \\
\hline 3 & 5-HTP & 30.0 & Subcutaneous & $2(0-4)$ & $2 \frac{1}{2}$ \\
\hline 4 & 5-НTP & 5.0 & Intravenous & $10(4-19)$ & 1 \\
\hline 4 & $\begin{array}{l}\text { Ringer's } \\
\text { solution }\end{array}$ & $1 \mathrm{ml}$ & Intraperitoneal & $3(0-5)$ & 1 \\
\hline \multirow[t]{2}{*}{4} & Ringer's & & & & \\
\hline & solution & $1 \mathrm{ml}$ & Subcutaneous & $1(0-2)$ & $2 \frac{1}{2}$ \\
\hline
\end{tabular}

suggest that the glycemic effect is due to a direct action of serotonin on the liver.

The in vitro glycogenolytic and vasomotor actions of serotonin were blocked by UML-491, a known serotonin antagonist, suggesting that these actions are specific for serotonin receptor sites within the liver. UML-491 also blocked the glycemic action of serotonin in vivo (Table III).

The present studies, showing that serotonin or its precursor, 5-HTP, stimulates hepatic phosphorylase activity, confirm the observations on serotonin of Mansour, Sutherland, Rall, and Bueding in the intact liver fluke, Fasciola hepatica (3), and of Vaughan in mammalian adipose tissue (25). The increased phosphorylase activity noted in the isolated rat liver may possibly be attributed to increased production of adenosine $3^{\prime}, 5^{\prime}$-phosphate, which in turn activates phosphorylase, and the observed glycogenolysis related in part to increased phosphofructokinase activity, a rate-limiting enzyme of glycolysis, since Mansour and Mansour have shown increases in both enzymes after serotonin in Fasciola hepatica (3, 26).

Serotonin has been shown to induce liberation of histamine (27). However, in 3 isolated liver perfusion experiments in which physiologic amounts of this amine (50 to $100 \mu \mathrm{g}$ per hour) were infused, no significant effects on glycogen metabolism were noted. These results suggest that the effects we observed with serotonin were probably not due to histamine release from hepatic mast cells.

Serotonin caused a prompt decrease in hepatic blood flow in doses exceeding $32 \mu \mathrm{g}$. The mechanism of this action remains unclear. A transient rise in the portal pressure occurs after peripheral or portal venous injection of serotonin in dogs (28). Since the "portal pressure" was kept constant by an overflow tube set at $14 \mathrm{~cm}$ of blood, evaluating changes in pressure in our perfusion experiments was impossible. As serial histologic studies showed no congestion of the liver after serotonin infusion, it is reasonable to assume that there was no significant constriction of the hepatic outflow tract. This interpretation is supported by the observation that in the perfused canine liver, serotonin constricts the hepatic artery and portal vein but not the hepatic vein (29). Other studies have shown that serotonin increases resistance in large arteries and veins in the foreleg of the anesthetized dogs (30), narrows the intrahepatic branches of the portal vein of the rat, as observed by serial angiography (31), and decreases hepatic blood flow in the perfused liver of the rat (32) and in man (33). From these reports, apparently the alterations in hepatic blood flow that we observed were probably due to vasoconstriction in the branches of the portal vein.

The glycogenolytic effect of serotonin was independent of its vasomotor action in 4 constant infusion experiments, since the former response 
occurred at doses of 4.1 to $16 \mu \mathrm{g}$ per minute, which had no effect on hepatic blood flow. Moreover, hyperglycemia followed 5 acute serotonin injections in experiments employing 16- $\mu$ g doses without any alteration in blood flow. Kobayashi and associates (32), who also perfused rat livers with serotonin, noted a prompt decrease in blood flow associated with hyperglycemia but only after very large doses of the amine $(4 \mathrm{mg})$. Because hyperglycemia did not occur when a small dose of serotonin (10 $\mu \mathrm{g}$ per minute) was given and a normal rate of blood flow maintained, they inferred that serotonin probably had no direct glycogenolytic action in the liver, a conclusion not supported by our studies. Moreover, it is remarkable that 5-HTP, unlike exogenous serotonin, had virtually no effect on hepatic blood flow, although it induced glycogenolysis, hyperglycemia, and stimulation of hepatic phosphorylase activity to a degree similar to the exogenously administered amine. Conceivably, when serotonin is given exogenously, it has immediate access to receptors in the smooth muscle cells of the vascular system; however, when serotonin is formed endogenously within hepatic cells, it encounters the phosphorylase system but may have no opportunity to reach reactive sites in the vascular tree in sufficient concentration.

Hemodynamic alterations alone or resulting hypoxemic conditions may have been partly responsible for the observed glycogenolysis in the 4 of 8 serotonin perfusion experiments in which decreased hepatic blood flow accompanied glycogenolysis. In the isolated perfused liver, however, slowing of blood flow per se does not result in hyperglycemia (34). Furthermore, under anoxic conditions introduced into this isolated system, phosphorylase activity is inhibited (20), whereas in the present studies the enzyme concentration actually increased in the presence of diminished blood flow induced by serotonin.

The present study has demonstrated a consistent 40 to $60 \%$ uptake of serotonin by the liver, both in the steady state and after rapid administration of the amine. These findings agree with those reported in unanesthetized dogs, in which hepatic clearance of serotonin ranged from $30 \%$ before infusion to as high as $80 \%$ of the infused dose when given continuously for 20 minutes
(35). However, in our experiments with prolonged continuous infusions of serotonin, the liver was no longer able to clear the infused amine by the end of the third hour. This suggests that monamine oxidase activity on serotonin in the rodent liver may not be so great as that in other species or in other tissues, such as brain, an interpretation supported by Zeller's observations (36).

The glycogenolytic effects of serotonin were somewhat delayed in onset compared to epinephrine or glucagon. This may be related, in part, to the rapid degradation of the amine by the liver during the initial 1 to 3 hours of infusion, rather than to release of other substances in the liver. The capacity of the liver to clear serotonin was limited by the third hour of infusion, which coincides with the time of maximal glycemic effect (Figure 3).

Both the isolated perfused liver and intact animal studies reported here are consistent with the suggestion made by Sjoerdsma that the levels of serotonin present in the portal venous blood are significantly higher and may be physiologically more active than those in the systemic circulation, where rapid serotonin metabolism and uptake by platelets prevent the accumulation of significant amounts of the free amine (37). Accordingly, under certain conditions the concentration of serotonin in the portal blood may reach sufficiently high levels to produce significant effects in the liver, whereas amounts of the free amine in the remainder of the circulation are still too low to produce systemic effects.

\section{Summary}

Endoportal administration of serotonin creatinine sulfate, in doses as low as $4^{10^{-4}} \mathrm{M}$, or endogenously synthesized serotonin derived from administered 5-hydroxytryptophan, produced glycogenolysis, hyperglycemia, and stimulation of hepatic phosphorylase activity in the isolated perfused rat liver. These actions of serotonin were independent of observed vasomotor effects of the amine on the liver. Tachyphylaxis was notable in this preparation with regard to the effect of serotonin on hepatic blood flow. The glycogenolytic and vasomotor actions of the amine were blocked by the infusion of a potent serotonin antagonist, 1-methyl- 
[methylergonovine], before serotonin administration. The glycemic effect observed in vitro was also noted in vivo when intact rats received serotonin or 5-hydroxytryptophan. Hepatic uptake of serotonin by the isolated liver was significant in the steady state and after rapid serotonin injection, but the limited capacity of the liver to clear the infused amine was exceeded after 3 hours of continuous serotonin infusion.

\section{Acknowledgments}

The authors wish to thank Rita Annunziata, Stephen Kimball, and Stephen Pachl for their technical assistance.

\section{References}

1. Mansour, T. E. The effect of serotonin and related compounds on the carbohydrate metabolism of the liver fluke, Fasciola hepatica. J. Pharmacol. exp. Ther. 1959, 126, 212.

2. Mansour, T. E. Effect of serotonin on glycolysis in homogenates from the liver fluke Fasciola hepatica. J. Pharmacol. exp. Ther. 1962, 135, 94.

3. Mansour, T. E., E. W. Sutherland, T. W. Rall, and E. Bueding. The effect of serotonin (5-hydroxytryptamine) on the formation of adenosine $3^{\prime}, 5^{\prime}$ phosphate by tissue particles from the liver fluke, Fasciola hepatica. J. biol. Chem. 1960, 235, 466.

4. Kobayashi, B., M. Ui, and Y. Warashina. The role of serotonin in carbohydrate metabolism. I. Glycemic effect of serotonin in rats. Endocr. jap. 1960, 7, 225.

5. Columbo, J. P., J. W. Weber, G. Guidotti, D. Kanameishi, and P. P. Foà. Liver phosphorylase in normal and adrenalectomized dogs treated with serotonin. Endocrinology 1960, 67, 693.

6. Galansino, G., G. d'Amico, D. Kanameishi, F. G. Berlinger, and P. P. Foà. Hyperglycemic substances originating in the pancreaticoduodenal area. Amer. J. Physiol. 1960, 198, 1059.

7. Gordon, P., and M. Lipton. Serotonin modification of blood sugar and glycogen compartments. Physiologist 1959, 2, 47.

8. Mirsky, I. A., G. Perisutti, and R. Jinks. The hypoglycemic action of metabolic derivatives of L-tryptophan by mouth. Endocrinology 1957, 60, 318.

9. Scaltrini, G. C. Il quadro emocitario periferico e la glicemia dopo 5-idrossitriptamina. Haematologica 1956, 41, 681.

10. Sirek, A. Nature and site of origin of the hyperglycemic substance released following an injection of growth hormone. Nature (Lond.) 1957, 179, 376.
11. Weitzel, G., U. Roester, E. Buddecke, and F. J. Strecker. Zingehalt und blutzuckersteigernde Wirkung von Organextrakten. Hoppe-Seylers Z. physiol. Chem. 1956, 303, 161.

12. Miller, L. L., C. G. Bly, M. L. Watson, and W. F. Bale. The dominant role of the liver in plasma protein synthesis. A direct study of the isolated perfused rat liver with the aid of lysine- $\epsilon-\mathrm{C}^{14}$. J. exp. Med. 1951, 94, 431.

13. Green, M., and L. L. Miller. Protein catabolism and protein synthesis in perfused livers of normal and alloxan-diabetic rats. J. biol. Chem. 1960, 235, 3202.

14. Nelson, N. A photometric adaption of the Somogyi method for the determination of glucose. J. biol. Chem. 1944, 153, 375.

15. Amin, A. H., T. B. B. Crawford, and J. H. Gaddum. The distribution of substance $P$ and 5-hydroxytryptamine in the central nervous system of the dog. J. Physiol. (Lond.) 1954, 126, 596.

16. Twarog, B. M., and I. H. Page. Serotonin content of some mammalian tissues and urine and a method for its determination. Amer. J. Physiol. 1953, 175, 157.

17. Good, C. A., H. Kramer, and M. Somogyi. The determination of glycogen. J. biol. Chem. 1933, $100,485$.

18. Hers, H. G. Etudes enzymatiques sur fragments hěpatiques; application à la classification des glycǒgenoses. Rev. int. Hépat. 1959, 9, 35.

19. Fiske, C. H., and Y. SubbaRow. The colorimetric determination of phosphorous. J. biol. Chem. 1925, 66, 375.

20. Levine, R. A., and R. Annunziata. Effect of hormones, adenine nucleotides, and anoxia on phosphorylase activity of perfused liver. Submitted for publication, Amer. J. Physiol.

21. Sokal, J. E., L. L. Miller, and E. J. Sarcione. Glycogen metabolism in the isolated liver. Amer. J. Physiol. 1958, 195, 295.

22. Hagen, $P$. The storage and release of catecholamines. Pharmacol. Rev. 1959, 11, 361.

23. Reid, G. Circulatory effects of 5-hydroxytryptamine. J. Physiol. (Lond.) 1952, 118, 435.

24. Correll, J. T., L. F. Lyth, S. Long, and J. C. Vanderpoel. Some physiologic responses to 5-hydroxytryptamine creatinine sulfate. Amer. J. Physiol. 1952, 169, 537.

25. Vaughan, M. Effects of hormones on phosphorylase activity in adipose tissue. J. biol. Chem. 1960, 235, 3049.

26. Mansour, T. E., and J. M. Mansour. Effects of serotonin (5-hydroxytryptamine) and adenosine $3^{\prime}, 5^{\prime}$-phosphate on phosphofructokinase from the liver fluke Fasciola hepatica. J. biol. Chem. 1962, 237, 629.

27. Feldberg, W., and A. N. Smith. Release of histamine by tryptamine and 5-hydroxytryptamine. Brit. J. Pharmacol. 1953, 8, 406. 
28. Gibertini, G., and R. Lodi. Richerche sperimentali sugli effetto del'a serotonina sulla pressione portale. Chir. Pat. sper. 1960, 8, 990.

29. Andrews, W. H. H., and K. R. Butterworth. The vascular action of 5-hydroxytryptamine on the canine liver. J. Physiol. (Lond.) 1958, 141, 38-P.

30. Haddy, F. J., M. Fleishman, and D. A. Emanuel. Effect of epinephrine, norepinephrine and serotonin upon systemic small and large vessel resistance. Circulat. Res. 1957, 5, 247.

31. Hesse, R., L. Demling, L. Zicha, and E. Schmid. Tierexperimentelle Untersuchungen zur portalen Zirkulation. Gastroenterologia (Basel) 1960, 94, 102.

32. Kobayashi, B., M. Ui, and Y. Warashina. The role of serotonin in carbohydrate metabolism. II.
The effect of serotonin on glycogen content of liver, heart and diaphragm in rats. Endocr. jap. 1960, 7, 239.

33. Chiandussi, L., F. Greco, D. Indovina, L. Cesano, A. Vaccarino, and F. Muratori. Effect of drug infusion on splanchnic circulation. II. Serotonin infusion in normal and cirrhotic subjects. Proc. Soc. exp. Biol. (N. Y.) 1963, 112, 326.

34. Brauer, R. W. Liver circulation and function. Physiol. Rev. 1963, 43, 115.

35. Drapanas, T., and J. C. McDonald. The direct removal of portal blood serotonin by the liver. Surg. Gynec. Obstet. 1963, 116, 481.

36. Zeller, E. A. Personal communication.

37. Sjoerdsma, A. Serotonin. New Engl. J. Med. 1959, 261, 181. 